ISBN 978-93-84468-75-0

International Research Conference on Literature, Humanities and Sociology (RCLHS-2016)

Oct.11-12, 2016 at Dubai (UAE)

\title{
Appraising the Roles of Ceramic Design and Conceptual Ceramics in the Society
}

\author{
Okewu, E. Jonathan1* and Dr. Chris Echeta2 \\ Department of Visual and Creative Arts, Federal University Lafia, Nasarawa State, Nigeria ${ }^{1,2}$ \\ jonathan.okewu@gmail.com
}

\begin{abstract}
Ceramics is a household name especially when it has to do with the utilitarian wares such as cups, plates, sanitary wares, floor and wall tiles and so on. The traditional use of ceramics as mentioned has so beclouded the idea of ceramics such that to a large extent, the conceptual part of ceramics becomes alien to many in the society even amongst professionals in the field. This article seek to take a look at the different roles of ceramics in the society apart from the traditional roles. It aspires to expand the vista of ceramic relevance on a conceptual platform. It will be obvious from this study that the importance of ceramics goes beyond the narrow angle which people are used to. Conceptualisation in the area lends a voice in a variety of social issues where utilitarian ceramics cannot operate. Conceptual ceramics provides a platform of creative freedom upon which the artist can express himself through morphological experimentation. This study shows that the conceptual aspect of ceramics has an unwavering relevance to the society of interrogating social issues.
\end{abstract}

Keywords: Ceramic Design, Conceptual Ceramics, Roles, Appraisal, Society

\section{Introduction}

Ceramics as practice in Nigeria institutions and personal studios is divided along lines of institutional and personal philosophy and believe. Some ceramic artists put greater emphasis on ceramic design that has to do with items of domestic utility, others are comfortable with conceptual ceramics for conveying messages while some practise either of the two in as much as it satisfies their philosophy. Either of the practises as mentioned are worthwhile and cannot be disputed, but the gross of the matter is that, the philosophy of some institutions and ceramic artists ignorantly relegate conceptual ceramics. This study has no bias for whatever practise of ceramics but due to association with the exponent of conceptual ceramics such as Chris Echeta and Ozioma Onuzulike, and coming to terms with the relevance of the practice to the society, it has become a venture to delve into to be able to use the medium of clay as a "voice" to interrogate societal issues and for the attainment of individual goals in the ceramic specialisation. The problem of this study is that much emphasis has been given to utilitarian ceramics to the detriment of conceptual ceramics, even among professionals in the specialisation when the relevance of conceptual ceramics is awe-inspiring. This study intends to bridge the gap for greater appreciation of conceptual ceramics.

This study is relevant to the sub-theme of the conference; 'Emerging Trends in Humanities and Social Sciences' because Ceramics is an arm of arts (it also has the science part) and can be located under the track of humanities and social sciences. The emerging trend brought forward by this study is the fact that ceramic artists are beginning to see a bigger picture by the social relevance of ceramics other than the traditional uses. This study is significant because it reveals the huge importance of ceramics in conceptual form that is able to 
interrogate societal issues for possible redress. A review of an international conceptual ceramic artist and her work gives a conceptual background to this study.

\section{Mutlu Başkaya Yağci}

Mutlu Başkaya Yağcı was born in Aydın in 1962. In Turkey, she is one of the young generation ceramic artists that add conceptual expressions into their works. Ozer (2012) reveals that one of the works of Mutlu Başkaya, who introduces a different aspect to Turkish ceramic art with his criticisms and satires, is his serial called 'Umut'(hope) (Fig. 1) that combines form and concept. "Unhappiness that is caused by daily politics over people, may turn into hope with little dreams when thought optimistically. In the forms created with this thought, ladder is the symbol of hope; however; when we feel pessimistic it talks about ambiguity and symbolizes the way from light to dark.

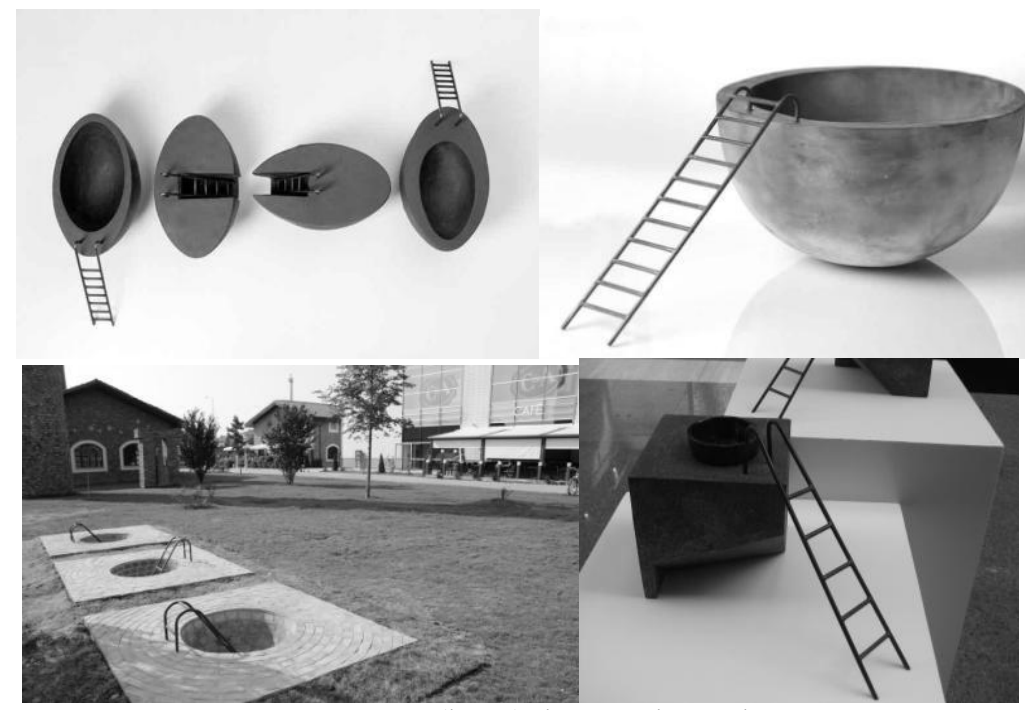

Fig. 1: 'Umut'(hope) by Mutlu Başkaya

Source: http://www.turkishpaintings.com/index.php?p=34\&l=1\&modPainters_artistDetaillD=2528

The word "Ceramics" according to Peterson and Peterson (2003), "has an enlarged connotation because of the extreme temperature ranges used by the space industry. Ceramic materials such as silicon carbide, uranium dioxide, and the like, have little in common with naturally occurring clays but are considered ceramics because of their high refractory nature". In a more precise term, Hamer and Hamer (2002) define Ceramics as clay product made permanent by heat.

According to Unal (2006), "ceramics which is an important subject of art and production beginning from the Neolithic era to today in Anatolia, is, at the same time, valuable for reflecting the production activities, sociological characteristics and life philosophy of many civilisations who have existed for thousands of years. Being a durable material clay is an important agent in the transfer of information from the past until today". Ecoma, (2011) opines that in Ceramic Art there are divergent directions, the traditional as well as the modern which constantly seek new forms and fusions. Ceramic comprises of object which may be sculptural, decorative, functional or conceptual and may be designed for social use, private pleasure, domestic or public environment.

Ceramic design could be referred to as ceramic items that are made primarily for use and could be mass reproduced to serve the society for household duties. This kind of utilitarian ceramics includes; tea set, cups, plates, saucers, storage Jars (Figs. 2, 3 and 4). This is remarkably different from the conceptual ceramics in their purpose.

Conceptual ceramics on the other hand, according to Caroun (2014), "is a contemporary form of artistic representation, in which a specific concept or idea, often personal, complex and inclusive, takes shape in an abstract, nonconforming manner, based upon a negation of aesthetic principles". Caroun (2014) further state that in Conceptual Art, "relationship between artist, artwork and viewer has been transformed. A work of 
"Conceptual Art" is not a mere narration of nature in its many forms; artist, through personal inference, utilizes the available elements of expression to depict not only the nature of objects, but often political, social and technological subjects as well. In many cases the spectator, and at times the artist themselves are integral parts of artwork and its basic concept".

"In spite of clay's possession of a very high horsepower for conveying loads of art ideas, its widespread use in the production of utilitarian vessels for domestic use appears to have drawn attention away from its expressive potentials and conceptual qualities. This is as true in Nigeria as it may be elsewhere. And this is perhaps why many art historians and writers, until recently, have not paid adequate attention to works in clay" (Onuzulike, 2009).

In Nigeria, few ceramic artist have explored into expressing themselves in conceptual ceramics to interrogate social issues in our society. The manner of their ceramic art works are mostly installations which are also called sculptural ceramics. They use their ceramic forms to illustrate succinct messages for humanity. Okpe (2008) mentions outstanding ceramic artists such as Abbas Ahuwan, Christ Echeta, Tony Umunna, and Ozioma Onuzulike who are working outside of pottery's rooted tradition of mere utilitarian objects.

For the purpose of this study, some conceptual ceramic pieces of Chris Echeta and Onuzulike Ozioma have been brought forward for discussion on how they capture social issues. To be able to do justice to the discussion of their works, it will be important to have some basic information about the conceptual ceramic artists.

\subsection{Chris Echeta}

Born in 1954, Echeta graduated in Fine and Applied Arts, (B.A. Hons), majoring in ceramics at the University of Nigeria, Nsukka in 1979, he specialized in the same area in his M.F.A. in 2001. He proceeded to do a Ph.D in Art History and graduated in 2011. After his first degree, Echeta had taught ceramics at the Auchi Polytechnic in 1980 and lectured there until 1985 when he resigned to go into private ceramic studio practice. Echeta practised ceramics for approximately two decades before he decided to get back into academics in 2003, In between this time terrain are more than thirty art exhibitions, commissions, awards and over thirty journal article publications and research projects undertaken by him. Echeta takes advantage of morphology of forms which he achieves through slab method of production, while achieving his surface quality with the imprint of jute bag material by rolling the slabs on the surface of the material. He goes further to enrich the body of his works by employing engobe designs. Echeta's works are mostly installations. Onuzulike (2008) reveals that "over the last two decades, Nigerian Chris Echeta has produced a large corpus of works, most of them pursuing social themes and satirizing poor leadership and the consequent suffering of the common man. According to Onuzulike, Echeta's thematic concerns can be traced to his experiences of the brutal Civil War (and which brought his early education to a halt from 1967 to 1970). Some of Echeta's conceptual ceramic pieces are discussed below;

The work of art; the "Sacking of a Generation", (Fig. 5), according to him dares to challenge both the 'shallowness' of policy formulation and the glaring lack of commitment at the implementation level. He concludes that if not so, this string of humanity would not have been forcibly uprooted from their ancestral inheritance forever. The metaphorical images draws attention to the artist and his art as well as the social relevance of his works (Echeta, 2013).

\subsection{Ozioma Onuzulike}

He was born on 17th February 1972 and he hails from Achi in Enugu State, Nigeria. Onuzulike holds a BA in Fine and Applied Arts (ceramics major), an MFA in ceramic art and a Ph.D. in the history of contemporary African art. His studio practice has been concerned with the production of new table ware designs (art pottery) and the use of ceramic elements in conceptual mixed-media sculptures that interrogate issues of armed conflicts, political violence (including imperialism) and human vulnerability. He has also applied his skills in poetry and art criticism to both his studio and theoretical engagements. As a clay artist, Onuzulike discovered that the many ways to work in clay relate very much to violent acts and to the troubles in many parts of the world. What is 
important for him in his work is to make it arrest people's attention and convey his repulsion for violence and man's inhumanity to man. According to Okoli (2014), works from Onuzulike's suyascape Project started showing in exhibitions from 2003 at French cultural Center in Lagos and reached its in 2008, when it showed at Skowhegan School of Painting and Sculpture, Skowhegan, Maine USA. Two of Onuzulike' conceptual ceramic works are discussed below;

The conceptual work of art "Suyascape" (Fig. 6) looks beyond the aesthetics of the formal qualities of a 'suyascape', it holds a strong metaphor for human dignity. When people gather at barbecues to buy and eat grilled meat, it is a metaphorical gathering for the celebration of human dignity - a silent recognition that animals should rather be killed, hacked, sliced and roasted in fire and not human beings. This is a direct reaction to the fact that we have witnessed gory sights in many parts of Africa, the Middle East and other parts of the world when people committed genocide or pogrom against others or engaged in wars and violent conflicts.

"More Casualties" (Fig. 7) looks beyond physical wars and terrorism, Onuzulike also began to see the idea of casualties in a new light. According to him, the bad roads across Africa generates lots of uncounted casualties on daily bases. Victims or casualties usually end up in mass graves or some ill-equipped orthopaedic hospitals. There are also lot of political casualties-those who are rigged out of elections or eliminated entirely by assassination.

\section{Discussion}

The practice of conceptual ceramics as revealed in this study is an emerging trend that negates the lay down principles of ceramic design that is meant for domestic usage. This practice goes to embody information that interrogate vital societal concerns. Conceptual ceramic works are generated through divers mode of production as suites the artist. The hand building methods of production in ceramics which include; pinching, coiling and slabing can be effectively employed in generating conceptual works. Throwing method of production can also be engaged in producing conceptual works by alteration after throwing on the potter's wheel. The desire to express ones feelings freely in the medium of clay and be able to engage equally and effectively in both competitions and exhibitions necessitates the production of conceptual ceramics. Works of this nature are relevant to the society in the sense that they engage and interrogate issues that affects the society to possibly effect a redress. Most times, people react to the work of this nature with a "layman's ignorance", not until they are educated about the conceptual meaning of the work. Conceptual ceramics are usually thought provoking to the spectator. The exponents of this kind of art strive to be able to contribute to the debate on national societal issues in their own way. By this exploit, the artist makes himself stand out and be different from the traditional ceramic artist. Since ceramic design has so flooded the society with Chinese technologies, it becomes difficult to attempt to compete or make remarkable impact in this area, especially in a technologically backward society. Unlike the dogmatic forgoing, conceptual ceramics has an unending arena of possibilities that anyone can comfortably and uniquely make a remarkable impact with.

The conceptual ceramic works as executed by Chris Echeta and Onuzulike Ozioma are not for domestic utility but rather of social utility for interrogating social issues and conveying messages. These works are meaningful ceramic pieces that have made their marks at different exhibition levels and venues for the public. Exhibition is vital to conceptual ceramic pieces because in such a way, there can be both objective and subjective revelations about the works. According to Oloidi (2011), art exhibitions are not only for economic gratification, they are a way of showing artists' creative professionality. All over the world and for ages, art exhibitions have been a political or ideological weapon against oppression, vices or anti-social activities. They are a propagandist instrument of change. They have been used to uplift the spirit of the depressed and lift up those who were trapped in deep valley of degradation and misery. An art exhibition induces critical verbal dialogue or academic discourse. It is evocative of knowledge and intellectualism. It is a concrete statement on life experience. 
The role of Ceramic design is in no doubt of importance in daily household chores, but in terms of social relevance, conceptual ceramics has a huge three dimensional effect that makes it to be able to interrogate social issues more advantageously and convincing. Oloidi (2011) opine that no civilised nation plays with, or disregards, the necessity for sculptural adornment, because apart from its appealing environmental aesthetics, such monumental works are a strong statement on the nations' political, cultural, socio-economic and other historic achievements. Oloidi further revealed that Washington D.C. is a very typical example of a city with greatly historic monuments, and this is why it is usually described as a city of monuments. Fine arts products all over the civilized world are part of government, corporate or any institutional architecture

\section{Conclusion}

Ceramics all round has gotten huge relevance to the society in divers ways as could be seen in ceramic design. It is obvious from this study that the importance of ceramics in the society cannot be over stretched but more importantly, the conceptual aspect of ceramics has an unwavering relevance to the society of interrogating social issues in a bid to bring about redress.

In line with the conference theme, this study has been able to contribute to knowledge by identifying and lending more voice to the unwavering social relevance of ceramics (conceptual ceramics) aside its conventional domestic relevance to the society.

\section{Recommendation}

This study recommends that conceptual ceramics as has been embraced by few ceramic artists and the viability seen, should be given recognition in institutions and private studios and more researches should be encouraged in this respect.

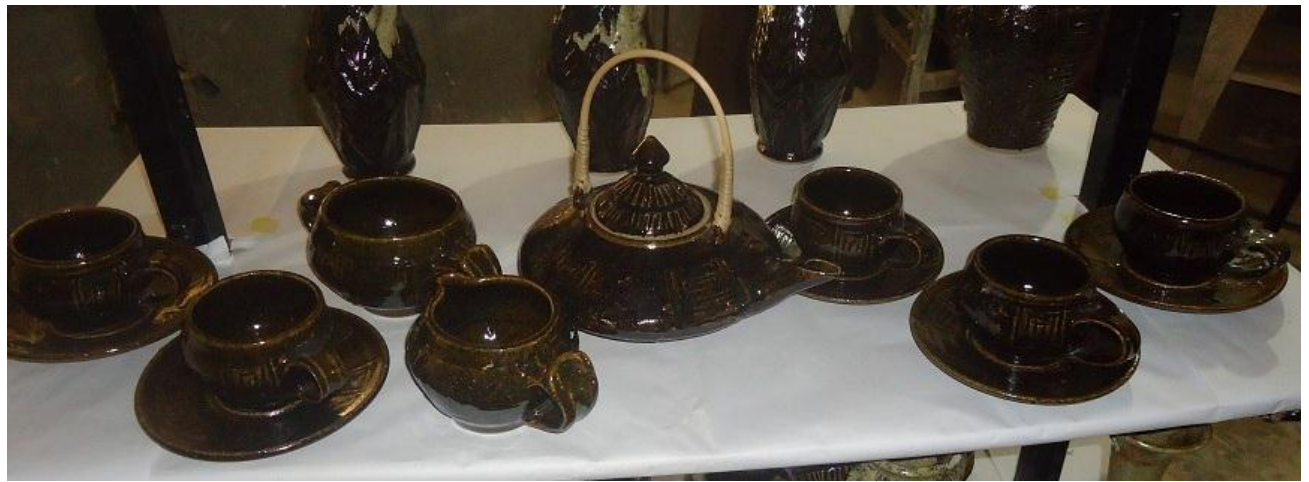

Fig. 2: 'Glazed Tea Set' Okewu Jonathan (2012)

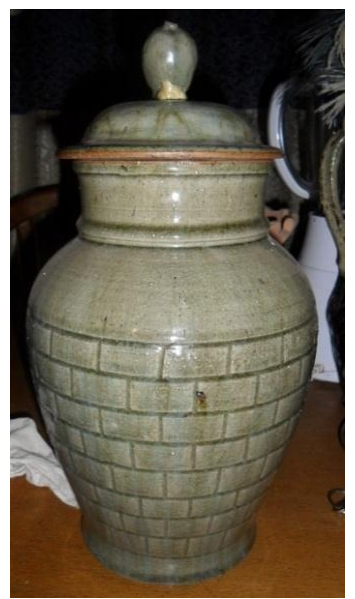

Fig. 3: Glazed storage Jar Okewu Jonathan (2012) 


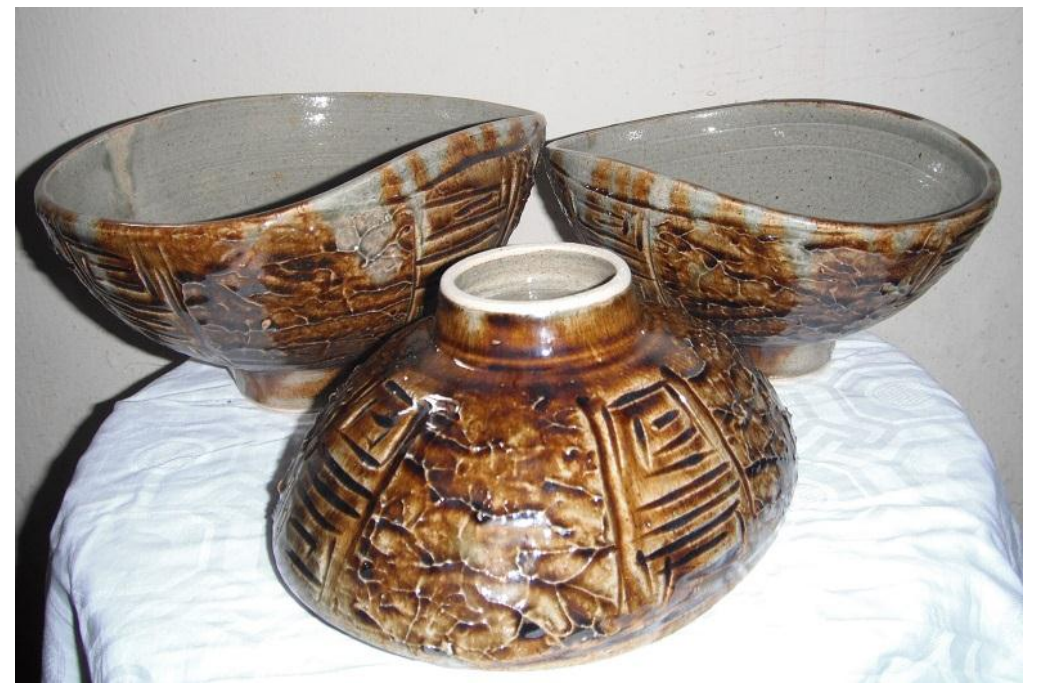

Fig. 4: Altered Bowls Okewu Jonathan (2012)

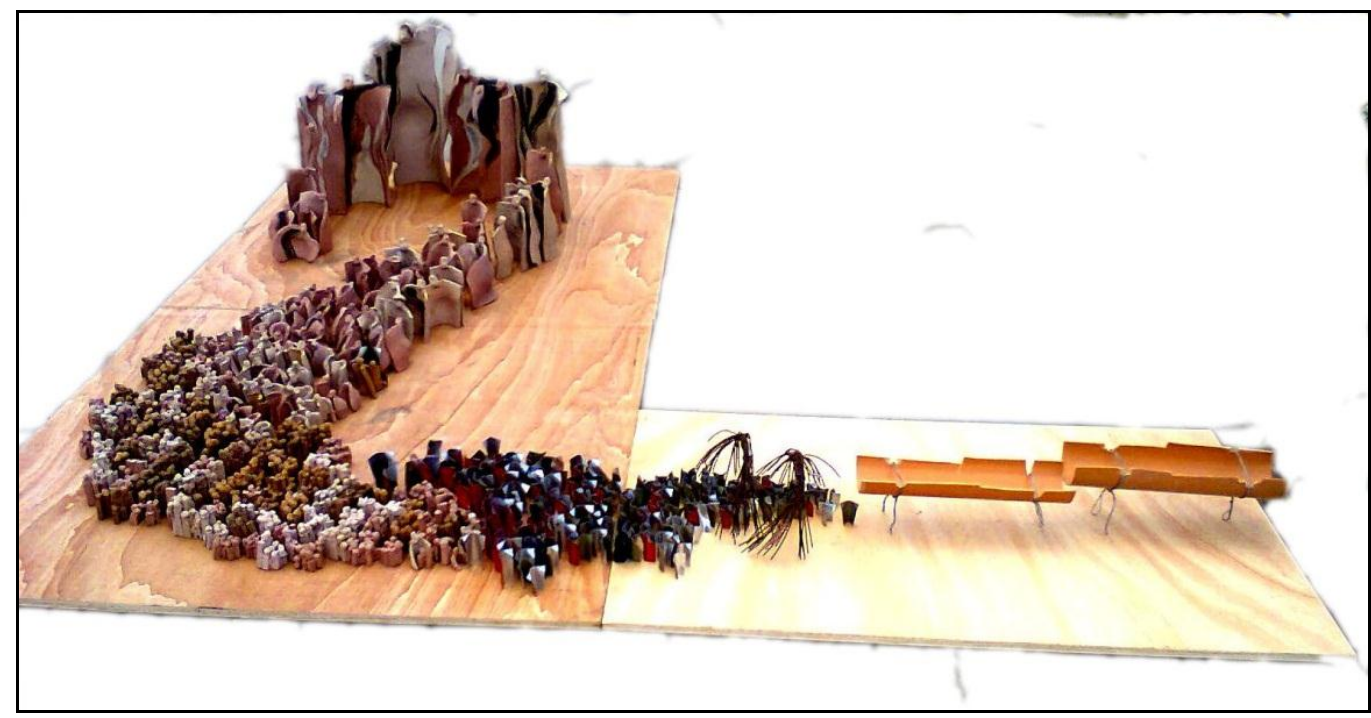

Fig. 5: 'Sacking of a Generation' Terracotta with engobe designs, metal/wire, plastic

Chris Echeta 2006-2012

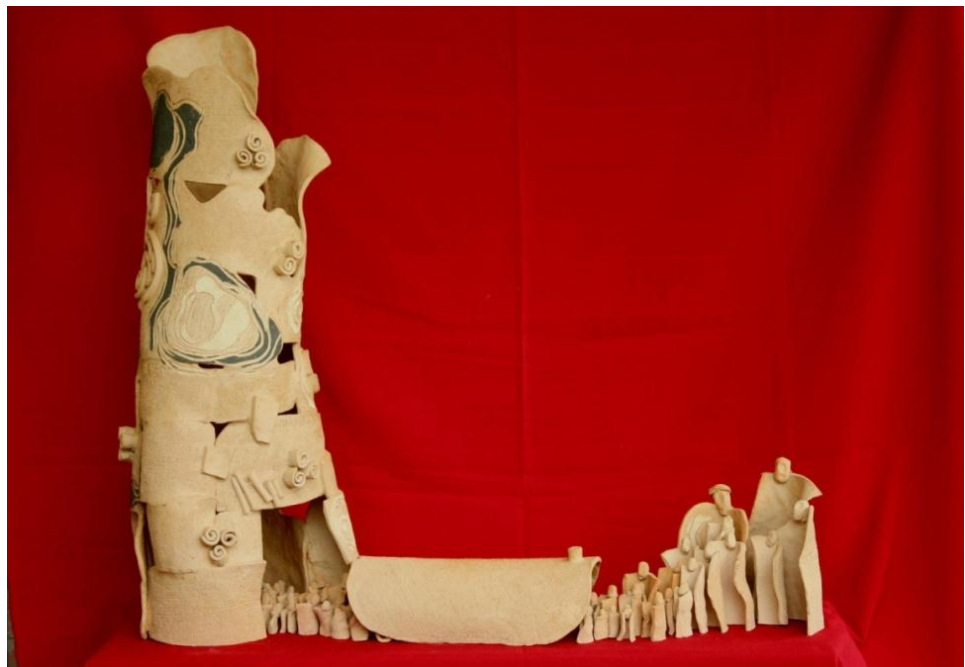

Fig. 6: "Aso Rock: One Question Each for the President" Terracotta with Engobe design Chris Echeta 2007 


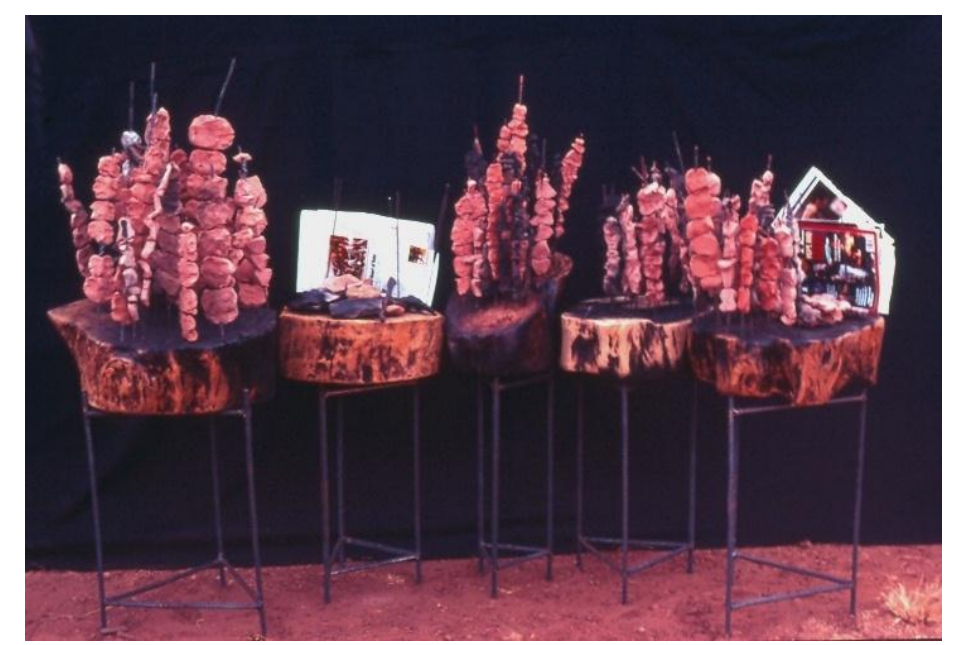

Fig. 7: 'Suyascape' terracotta, metal and wood, Onuzulike O. 2003

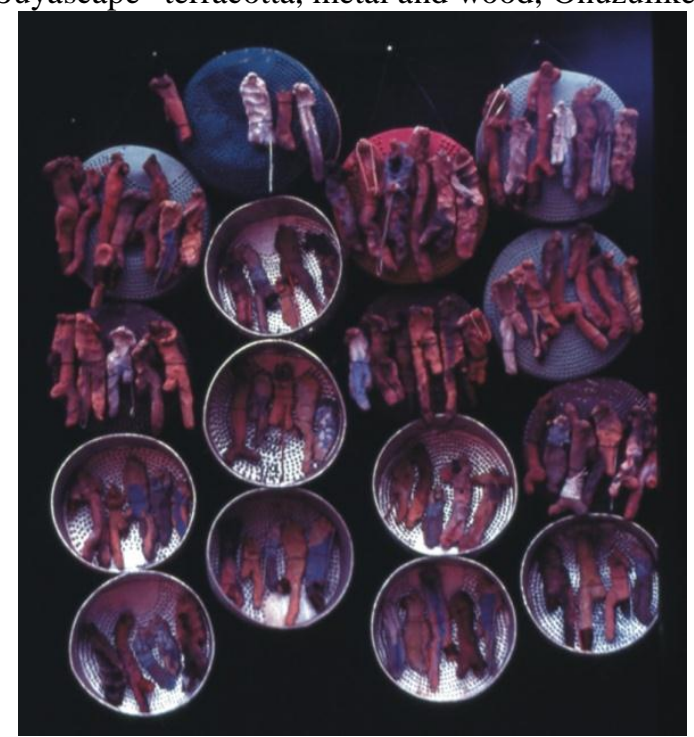

Fig. 8: "More Casualties" Terracotta, Binding Wire and Akpu Colanders Onuzulike Ozioma 2003

\section{References}

[1] Caroun.com, (2014), "Conceptual Art", $\quad$ retrieved $12 \quad$ November, 2015 http://www.caroun.com/art/conceptualart/conceptualart.html

[2] Echeta C. (2013), "The Sacking of a Generation", Ceramics Technical, No. 37, PP. 56-61

[3] Ecoma V.E. (2011), "Interpreting Past Cultures and Civilisations Through Ceramics", Ashakwu Journal of Ceramics, Vol. 8, PP. 72-77

[4] Hamer F. and Hamer J. (2002), "The Potter's Dictionary of Materials and Techniques", Pitman Publishing Ltd, Pennsylvania,

[5] Oloidi O. (2011), "The Rejected Stone: Visual Arts in an Artistically Uninformed Nigerian Society". An Inaugural Lecture delivered on April 28, at the University of Nigeria. Published by University of Nigeria, Nsukka

[6] Onuzulike O. (2009), "Towards the Unique and the Light-Weight: Carving the Ceramic Vessels", Cpan Journal of Ceramics, Nos. $2 \&$ 3, PP. $54-59$

[7] Onuzulike O. (2008), "Chris Echeta's Ceramic Chronicles of Nigeria", reprieved 12 November, 2015. http://www.criticalceramics.org/oldsite/articles/echeta.shtml 
[8] Ozer G. (2012), Conceptual Approaches in Contemporary Ceramic Art, ATINER's Conference Paper Series ART2012-0105, retrieved 16 September, 2014. http://www.atiner.gr/papers/ART2012-0105.pdf

[9] Peterson S. and Peterson J. (2003), "The Craft and Art of Clay", Laurence King Publishing, Great Britain.

[10] Unal S. (2006), "Primitive Pottery in Serinhisar Anatolia", Turkey. Ceramics Technical, No. 22. Paddington, Australia. PP. 59-64 